\title{
Numerical Simulation of Atom-Transfer Radical Polymerization of tert-butyl Methacrylate
}

\author{
Fiorella Zenaida Fernandez Herrera ${ }^{a, b}$, Roniérik Pioli Vieira ${ }^{b * \mathbb{D}}$ \\ ${ }^{a}$ Facultad de Ingeniería Química, Universidad Nacional del Callao, Callao, Perú \\ ${ }^{b}$ Departamento de Engenharia de Materiais e de Bioprocessos, Faculdade de Engenharia Química, \\ Universidade Estadual de Campinas, Campinas, São Paulo, Brasil
}

Received: May 12, 2019; Accepted: June 29, 2019

\begin{abstract}
Block copolymers based on tert-butyl methacrylate (tBMA) have many uses, such as thermoresponsive polymers, amphiphilic copolymers, and many applications in the medical field. Atom-transfer radical polymerization (ATRP) is the main technique to produce these controlled macromolecular architectures. This paper provides a simplified kinetic modeling and computational study of tBMA ATRP. The main objective is to understand the behavior of chemical species in the reaction and its influence on polymer properties (molecular weight and dispersity). The proposed model presented good reproducibility of the experimental data, with average errors less than $10 \%$. The simulations indicated a strong initiator and catalyst concentration dependence on the monomer conversion. Although the highest initiator proportion induced a dispersity increase in conversions less than $20 \%$, in general, for tBMA ATRP, the range of operational condition cannot affect dispersity directly. In addition, our finds about the effect of $\mathrm{K}_{\mathrm{eq}}$ on polymer properties indicated that to conduct the reaction using catalyst systems with $\mathrm{K}_{\mathrm{eq}}$ around $10^{-5}-10^{-6}$ would provide very low dispersity polymers in a fast reaction time.
\end{abstract}

Keywords: ATRP, tert-butyl methacrylate, simulation, modeling.

\section{Introduction}

Recent achievements in polymer engineering have provided conditions for the synthesis of materials with specific properties for application in microelectronic devices ${ }^{1,2}$, cosmetics $^{3}$, paints ${ }^{4}$, UV-absorbents coatings and adhesives ${ }^{5,6}$, and mainly in the medical field ${ }^{7-10}$. Until the early 1990s, materials with controlled architecture were mainly synthesized by ionic polymerization ${ }^{11}$. Despite the advantage in reducing chain transfer and termination reactions, these techniques are very sensitive to impurities ${ }^{12}$. Alternatively, free-radical polymerization (RP) is more robust for industrial operations, which use impure materials and, in many cases, require a wide operating temperature range. Even having this potential for industrial processing, the lifetime of radicals in propagation is very short, hindering macromolecular structure control ${ }^{12}$.

With the recent emergence of reversible-deactivation radical polymerization (RDRP) techniques, it was possible to extend the radicals livingness by including chemical species that provide a period of "dormancy" between short periods of activity through a reversible mechanism ${ }^{12}$. Thus, it was possible to add the advantages of radical polymerization with the characteristic of macromolecular control of ionic polymerizations. There are three mechanisms based on RDRP: nitroxide-mediated radical polymerization (NMP) ${ }^{13}$, reversible addition-fragmentation chain transfer radical polymerization (RAFT) ${ }^{14}$, and atom-transfer radical polymerization (ATRP) ${ }^{15}$.
The ATRP technique presents a great advantage over other RDRP, expressed by the range of polymerizable monomers, initiators and solvents, most of which are commercially available ${ }^{12}$. It is a very attractive technique due to the ease of experimental conduction, with low reaction temperature ${ }^{16}$. In addition, the ATRP technique provides the synthesis of specific forms for the preparation of differentiated architectures, such as block copolymers, stars, brushes etc. ${ }^{17}$. The desired architecture and narrow molecular weight distribution (MWD) provided the ability to design molecules for multiple applications, such as adhesives ${ }^{18}$, cellulosebased elastomers ${ }^{19}$, drug delivery systems ${ }^{20,21}$, antifouling surfaces ${ }^{22}$, lubricants ${ }^{23}$, dispersants ${ }^{24}$, etc.

Block copolymers based on tert-butyl methacrylate (tBMA) have many uses, such as in its incorporation in thermo-responsive polymers with a lower critical solution temperature ${ }^{25}$, peptide-polymer conjugates with selforganizing property and biological activities ${ }^{26}$, well-defined amphiphilic graft copolymers ${ }^{27}$, polymers with very good electrochemical ${ }^{28}$ and magnetic performances ${ }^{29}$, and also many applications in the medical field ${ }^{30-33}$. This recent application growth of tBMA-based materials suggests a need for in-depth knowledge of synthesis by ATRP. Many of the published papers present experimental results without a brief description of optimized conditions or an analysis of the reaction conditions influence on the material properties, and few research papers deals with tBMA simulations. Some traditional examples of works dealing with ATRP modeling for several monomers can be found in the literature ${ }^{34-46}$. 
The aim of this study is to simulate the performance of the ATRP of tert-butyl methacrylate, covering a wide range of experimental conditions, evaluating such influence on molecular weight, dispersity, and kinetic behavior. Our simulations were carried out with the intention to further test and validate the simplified kinetic model proposed for the ATRP of tBMA. Our approach included reproducing experimental data from literature and also predicting the behavior at conditions different from those addressed experimentally.

\section{Mathematical Modeling and Simulations}

A simplified mathematical modeling was developed using the kinetic mechanism described in Table 1. In this mechanism, the primary radical $\left(\mathrm{R}^{*}\right)$ is originated from initiator oxidization $(\mathrm{RX})$, catalyzed by the activator $(\mathrm{C})$ and with possible reaction to monomers $(\mathrm{M})$ to achieve further propagation. The propagating radicals $\left(\mathrm{P}_{\mathrm{n}}^{*}\right)$ can be reversibly deactivated by $\mathrm{XC}$ to form the dormant species $\left(\mathrm{P}_{\mathrm{n}} \mathrm{X}\right)$. For model simplicity, only the termination by disproportionation was considered. Other side reactions were neglected in this study. From the elementary reactions in Table 1, mass balance equations for all reacting species in a batch reactor are described by Equations 1-6.

$$
\begin{gathered}
\frac{d[R X]}{d t}=-k_{a}[R X][C]+k_{d a}[X C]\left[R^{*}\right] \\
\frac{d[C]}{d t}=-k_{a}[R X][C]+K_{d a}[X C]\left[R^{\cdot}\right] \\
-k_{a}\left[P_{n} X\right][C]+k_{d a}[X C]\left[P_{n}^{\cdot}\right] \\
\frac{d\left[P_{n}^{\cdot}\right]}{d t}=-k_{p}\left[P_{n}^{\cdot}\right][M]-k_{t r}\left[P_{n}^{\cdot}\right][M] \\
-k_{t d}\left[P_{n}^{\cdot}\right]\left[P_{m}^{\cdot}\right]-k_{d a}[X C]\left[P_{n}^{\cdot}\right]+k_{a}\left[P_{n} X\right][C] \\
\frac{d\left[P_{n} X\right]}{d t}=k_{d a}[X C]\left[P_{n}^{\cdot}\right]-k_{a}\left[P_{n} X\right][C] \\
\frac{d[M]}{d t}=-k_{p}\left[P_{n}^{\cdot}\right][M]-k_{t r}\left[P_{n}^{\cdot}\right][M]
\end{gathered}
$$

$$
\frac{d\left[P_{n}\right]}{d t}=k_{t d}\left[P_{n}^{\cdot}\right]\left[P_{m}^{\cdot}\right]+k_{t r}\left[P_{n}^{\cdot}\right][M]
$$

From Equations 1-5, the method of moments was used to predict number-average molecular weight, weight-average molecular weight, and dispersity. Moments equations were calculated by Equations 7-9, in which were developed equations of order "zero", "one", and "two" for each species ("living", "dormant", and "dead" polymers) (Appendix).

$$
\begin{gathered}
\mu_{i}=\sum_{n=0}^{\infty} n^{i}\left[P_{n}^{\cdot}\right] \\
\delta_{i}=\sum_{n=0}^{\infty} n^{i}\left[P_{n} X\right] \\
\lambda_{i}=\sum_{n=0}^{\infty} n^{i}\left[P_{n}\right]
\end{gathered}
$$

$\mu_{i}$ is the moment of order " $i$ " for the "living" polymer with chain length equals " $n$ "; $\delta_{i}$ is the moment of order "i" for the "dormant" polymer with chain length equals " $n$ "; and $\lambda_{i}$ is the moment of order " $\mathrm{i}$ " for the "dead" polymer with chain length equals " $n$ ".

The zero ${ }^{\text {th }}$ order moment physically represents the concentration of polymer chains in the system. The first order moment represents the concentration of monomeric units that have been incorporated into the polymer chains. The zero ${ }^{\text {th }}$ and first moments can be related to the polymer chain length distribution ${ }^{47}$. Thus, average properties were obtained by equations 10-12.

$$
M_{n}=M M \times \frac{\left(\mu_{1}+\delta_{1}+\lambda_{1}\right)}{\left(\mu_{0}+\delta_{0}+\lambda_{0}\right)}
$$

$$
\begin{gathered}
M_{w}=M M \times \frac{\left(\mu_{2}+\delta_{2}+\lambda_{2}\right)}{\left(\mu_{1}+\delta_{1}+\lambda_{1}\right)} \\
Ð=\frac{M_{W}}{M_{n}}
\end{gathered}
$$

$M_{n}$ is the number-average molecular weight; $M_{w}$ is the weight-average molecular weight; and $Đ$ is the dispersity.

Table 1. kinetic modeling and parameter values.

\begin{tabular}{lcccc}
\hline Reaction type & Reaction & Constant & Value & Reference \\
\hline Initiation & $R X+C \stackrel{k_{0}}{\longrightarrow} R+X C$ & $\mathrm{~K}_{\mathrm{eq} 0}$ & $1.8 \times 10^{-7}$ & This study \\
Propagation & $P_{n}^{\cdot}+M \stackrel{k p}{\longrightarrow} P_{n+1}^{\cdot}$ & $\mathrm{k}_{\mathrm{p}}$ & $\begin{array}{c}2.4 \times 10^{6} \mathrm{exp}(- \\
2658 / \mathrm{T})\end{array}$ & {$[34]$} \\
Polymer activation/deactivation & $P_{n} X+C \stackrel{k a l k d a}{\longrightarrow} P_{n}^{\cdot}+X C$ & $\mathrm{~K}_{\mathrm{eq}}$ & $1.8 \times 10^{-7}$ & {$[33]$} \\
Termination by disproportionation & $P_{n}^{\cdot}+P_{m}^{\cdot \stackrel{k t d}{\longrightarrow}} P_{m}+P_{n}$ & $\mathrm{k}_{\mathrm{td}}$ & $\begin{array}{c}2.57 \times 10^{10} \mathrm{exp}(- \\
2943 / \mathrm{T})\end{array}$ & {$[35]$} \\
\hline
\end{tabular}


To validate de mathematical modeling, the polymerization of tert-butyl methacrylate (tBMA) by Zhao el al. ${ }^{48}$ was considered. The authors conducted the homopolymerization of methyl methacrylate (MMA) and tBMA, and also the copolymerization of these two monomers using p-Toluenesulfonyl chloride ( $\mathrm{pTsCl}$ ) as initiator, $\mathrm{CuCl}$ and 4,40-Dinonyl-2,20-bipyridyl (dnNbpy) as catalyst system at $100{ }^{\circ} \mathrm{C}$. In all polymerization, the molar ratio of $[\mathrm{p}-\mathrm{TsCl}]_{0} /[\mathrm{CuCl}]_{0} /[\mathrm{dnNbpy}]_{0}$ was set to be $1 / 1 / 2$. The initial monomer content was $70 \mathrm{wt} \%$ and $30 \%$ of p-Xylene. Based on these experimental conditions, to conduct the modeling validation of this study, the reactants concentrations expressed in Table $2^{48-50}$ were used.

To analyze a wide range of reaction conditions that are not described in the literature, after the model validation, simulations were performed considering a multivariate analysis of monomer, catalyst, and initiator concentrations, as proposed by Vieira et al. ${ }^{51}$. Its effects were evaluated on the kinetics of monomer consumption as well as on polymer average properties (molecular weight and dispersity). In addition, the effect of the equilibrium constants on the chemical species concentration profile, as well as materials properties were evaluated. The $\mathrm{k}_{\mathrm{a}}$ was kept fixed, while the $\mathrm{k}_{\mathrm{da}}$ was being increased. This analysis is of great importance in the choice of catalyst, since each catalytic system will present a different value. Based on this information, it was possible to identify interesting values for the process conduction and the best choice of catalytic system.

\section{Results and Discussion}

\subsection{Model validation}

This section presents the comparison of experimental data from literature and simulations using the mathematical modeling developed. The simulated monomer conversion, number-average molecular weight, and dispersity were compared with the experimental data reported by Zhao et al. ${ }^{48}$ at different experimental conditions. Attention was paid to the relation between the broadness and the skewness of the polymer dispersity and its average molecular weight.

Figure 1 compares the experimental data and simulation results of the monomer conversion as a function of time at $100{ }^{\circ} \mathrm{C}$, considering two different proportions of catalyst $(0.36 \%$ and $0.5 \% \mathrm{CuCl})$. Monomer conversion evolution as a function of polymerization time can be related to the change of the total radical concentration and deactivator concentration of persistent species.
Analyzing Figure 1, it is possible to see that experimental data are almost fully represented by the simulations. For both situations, the percentage reproduction error values of the experimental data using the modeling proposed in this work were calculated. An error of $4.56 \%$ and $6.58 \%$ was obtained for the reproductions using 0.5 and $0.36 \% \mathrm{CuCl}$, respectively. It can be seen from this analysis that the model is not only able to reproduce the monomer conversion quite satisfactorily, but it can also evaluate the effect of the catalyst concentration on monomer conversion.

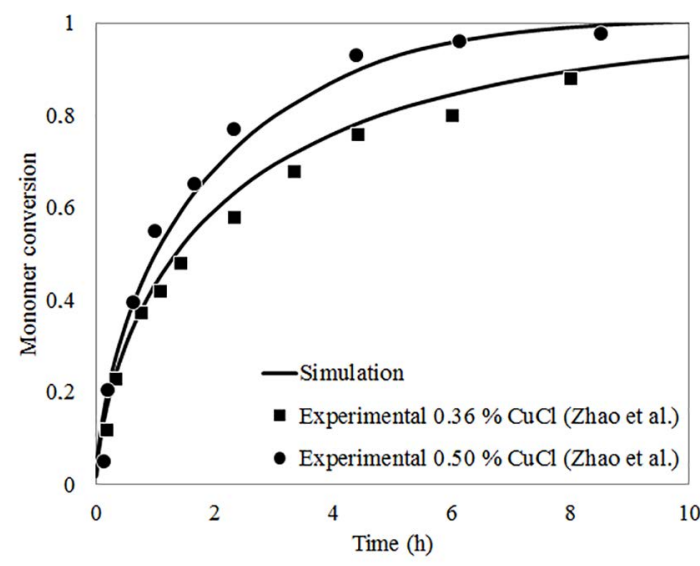

Figure 1. Comparison of experimental and simulated monomer conversion as a function of time of tBMA ATRP at $100{ }^{\circ} \mathrm{C}$ with molar ratio $[\mathrm{tBMA}]_{0}:[\mathrm{I}]_{0}:[\mathrm{C}]_{0}$ equals $140: 1: 1(0.36 \% \mathrm{CuCl} /$ weight $)$ and 140:1:1.4 (0.5\% CuCl / weight). Experimental data from the literature (Zhao et al., 2008)

Figure 2 illustrates the experimental data and simulations for the evolution of number-average molecular weight as a function of monomer conversion. From this figure, it is possible to notice that the simulated molecular weights are in agreement with the experimental data. However, at high monomer conversions, there was a deviation from experimental data that can be explained by the simplicity of the modeling used. The model did not consider gel effect and also considered that only termination by disproportionation was occurring. In addition, other chain transfer reactions (to dimer, primary radicals, etc.) were not considered, which could contribute for the poor reproducibility at high monomer conversions. In despite of the simplifications described, a linear increase of $M_{n}$ as a function of monomer conversion was observed, confirming the controlled polymerization, with general good reproducibility by simulations.

Table 2. Set of reaction conditions used in model validation at $100{ }^{\circ} \mathrm{C}$.

\begin{tabular}{ccccc}
\hline Validation & {$[\mathrm{TBMA}]_{0}\left(\mathrm{~mol} \mathrm{~L}^{-1}\right)$} & {$[\mathrm{p}-\mathrm{TsCl}]_{0}\left(\mathrm{~mol} \mathrm{~L}^{-1}\right)$} & {$[\mathrm{CuCl}]_{0}\left(\mathrm{~mol} \mathrm{~L}^{-1}\right)$} & {$\left[\mathrm{dnNbpy}_{0}\left(\mathrm{~mol} \mathrm{~L}^{-1}\right)\right.$} \\
\hline Monomer conversion as a function of time & 4.79 & 0.034 & 0.034 & 0.068 \\
Number-average molecular weight and dispersity & 4.79 & 0.017 & 0.017 & 0.034 \\
\hline
\end{tabular}




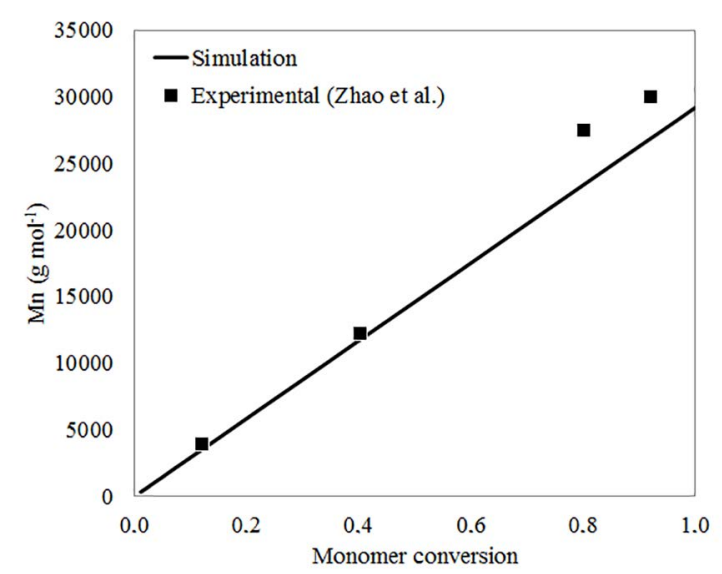

Figure 2. Comparison of experimental and simulated numberaverage molecular weight development as a function of monomer conversion of tBMAATRP at $100^{\circ} \mathrm{C}$ with $[\mathrm{tBMA}]_{0}:[\mathrm{I}]_{0}:[\mathrm{C}]_{0}$ equals 280:1:1. Experimental data from the literature (Zhao et al., 2008)

Figure 3 illustrates that the dispersity assumes low values for both the experimental and the simulation results. There was a very good reproducibility of experimental data by simulations. Fischer described that when considering only activation, deactivation, propagation, and termination by disproportionation in ATRP mechanisms (neglecting diffusional limitations), dispersity tends to assume low values in a wide range of monomer conversion ${ }^{52}$, according to the results found in the simulations and experiments described in Figure 3. In addition, it is important to highlight here that number- and weight-molecular weight distributions are mainly determined by the dormant polymer and only slightly influenced by the dead polymer ${ }^{53,54}$. In addition, although polymer dispersity is very useful to characterize the broadness of number-molecular weight distributions, it cannot be used to describe broadness of weight-average molecular weight ${ }^{55}$.

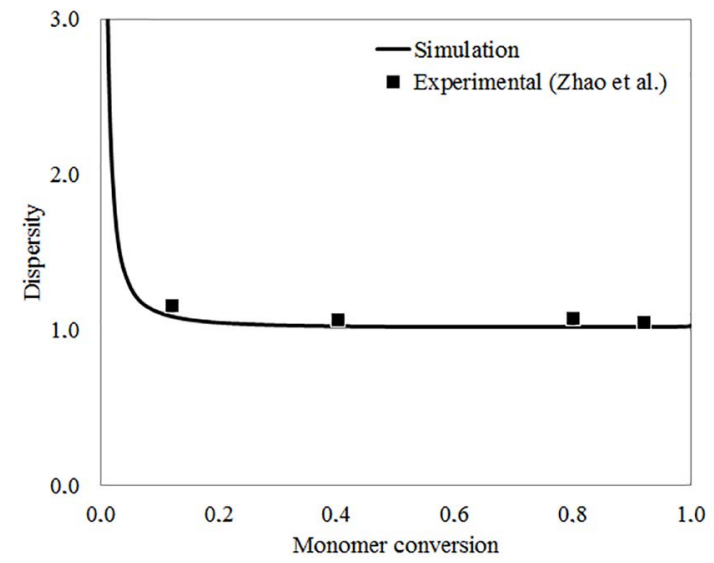

Figure 3. Comparison of experimental and simulated dispersity as a function of monomer conversion of tBMA ATRP at $100{ }^{\circ} \mathrm{C}$ with $[\mathrm{tBMA}]_{0}:[\mathrm{I}]_{0}:[\mathrm{C}]_{0}$ equals $280: 1: 1$. Experimental data from the literature (Zhao et al., 2008)

\subsection{Analysis of reactants concentration on the average properties}

Figure 4 (a) and (b) shows that monomer concentration does not influence on its conversion, confirming de pseudofirst order behavior. An increase of initiator concentration increases the polymerization rate. This situation is quite common, since high concentration of initiator produces more "living" polymers that present a direct influence on the rate (as can be seen in monomer consumption kinetic expression). In addition, it is important to note that tBMA conversion is also dependent on catalyst concentration, since the concentration of this reagent is present in the expression of the activation rate of the polymer chains which will lead to an increase in the concentration of propagating radicals. Note that the same variations in the ratios of initiator and catalyst provide equal effects on monomer conversion. These results are very important considering reactor design issues, for example analysis of residence time.

Figure 4 (c) and (d) illustrates that a higher initiator concentration tends to reduce the polymer number-average molecular weight. This characteristic was expected based on the classic concept of one initiator-one polymer chain. However, the multivariate analysis did not influence considerably on dispersity at high monomer conversions (see Figure 4 (e) and (f)). In both figures, for the highest proportion of initiator there was a dispersity increase in conversions less than $20 \%$ (circled regions). This behavior can be attributed to the amount of radicals formed in initial stages. Many of the "living" polymers formed are available for termination, and the deactivation step could still not have been achieved, which could be contributed for the higher dispersities. In addition, the simulations also demonstrate the increase in dispersity with decreasing catalyst level, indicating the existence of a threshold value for the catalyst level in cases where the level of control over chain length is important. Despite this behavior at low monomer conversions, in general, for tBMA ATRP, the range of operational condition cannot affect directly on dispersity, which is a very good result in terms of material processability and applications.

\subsection{Analysis of the equilibrium constant effect on chemical species behavior and average properties}

In addition to the termination, propagation and chain transfer reactions, ATRP also has the equilibrium reaction between dormant chains and polymer radicals. The rate constant of the equilibrium reactions depends on monomer and chain end type, polymerization temperature, catalyst type and polymerization medium. The equilibrium constant $\left(\mathrm{K}_{\mathrm{eq}}\right)$ is the ratio of the activation $\left(\mathrm{k}_{\mathrm{a}}\right)$ to the deactivation $\left(\mathrm{k}_{\mathrm{da}}\right)$ rate constants. 


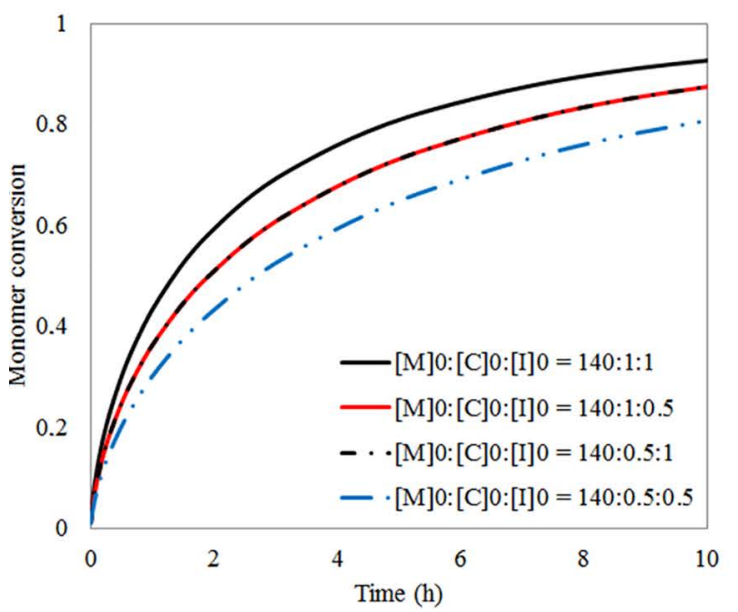

(a)

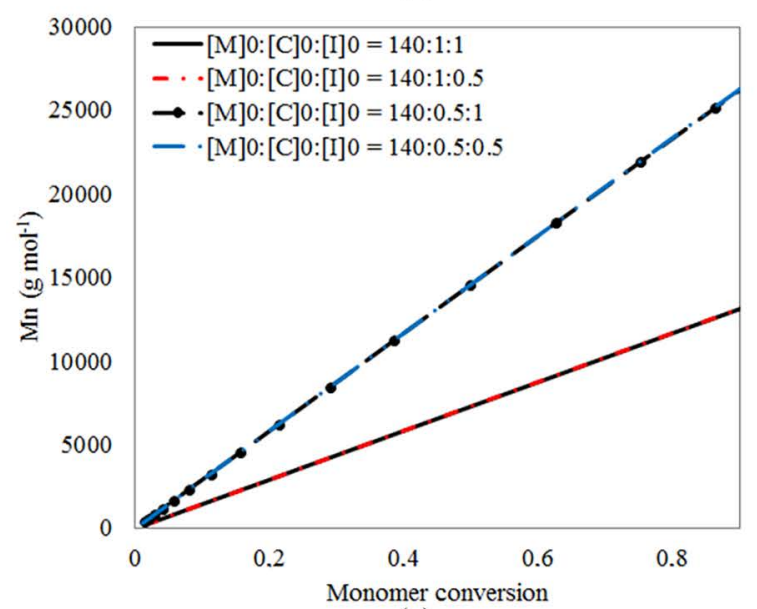

(c)

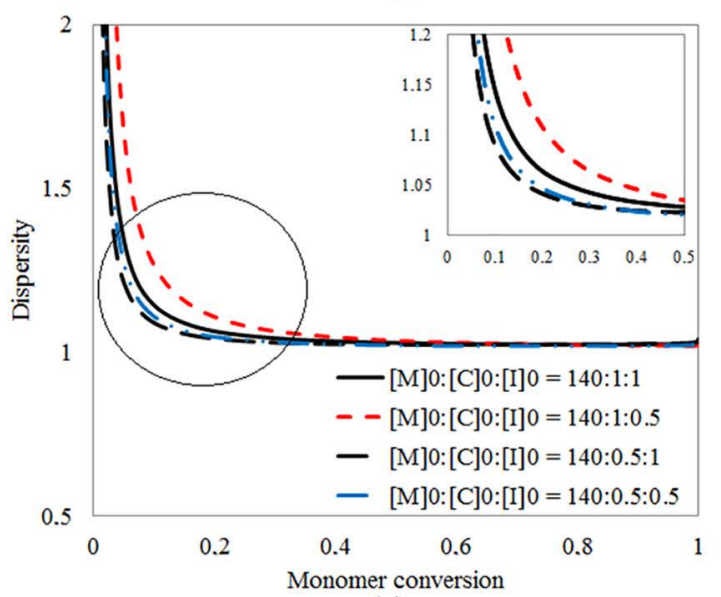

(e)

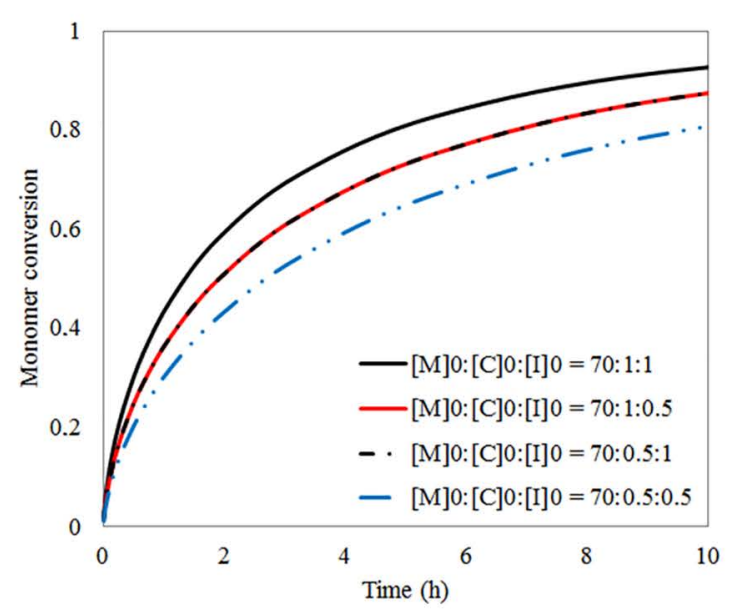

(b)

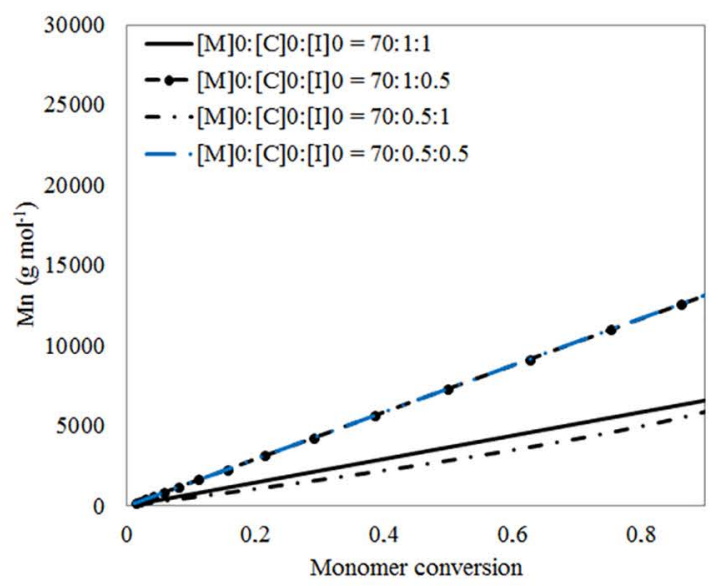

(d)

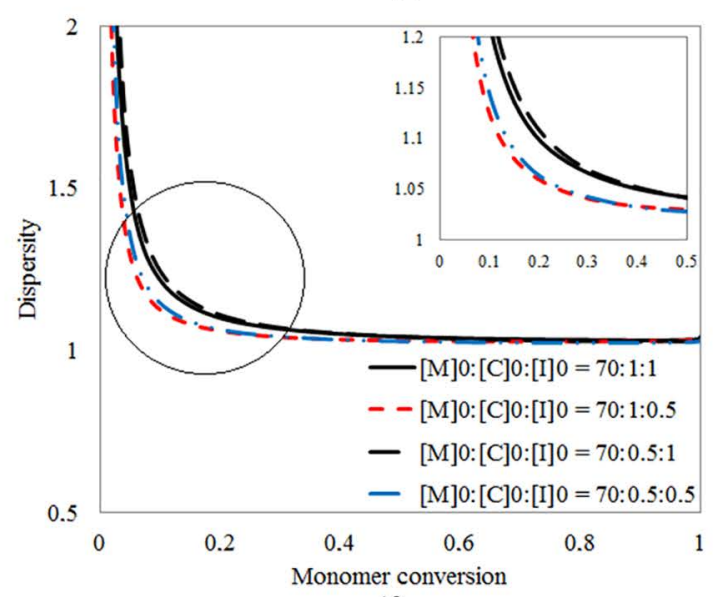

(f)

Figure 4. Analysis of reaction conditions on monomer conversion and polymer properties

Figure 5 shows the effect of $\mathrm{K}_{\mathrm{eq}}$ ranging from $10^{-4}$ to $10^{-6}$ (typical values for commercial ATRP systems) on (a) dispersity, (b) monomer conversion and (c) number-average molecular weight. In these figure, $\mathrm{k}_{\mathrm{da}}$ was changed while $\mathrm{k}_{\mathrm{a}}$ was kept constant, and the same proportion of reactants were maintained for each simulation.
For equilibrium constant equals $1.8 \times 10^{-5}$, dispersity values (Figure 5 (a)) increase and move away from the unit, reaching a value of 1.3. However, it can still be considered controlled polymerization (dispersity less than 1.5 ) even though a better control of the polymerization would be achieved by equilibrium constants lower than this value (see dispersity for $\mathrm{K}_{\mathrm{eq}}=1.8 \times 10^{-6}$ ). 


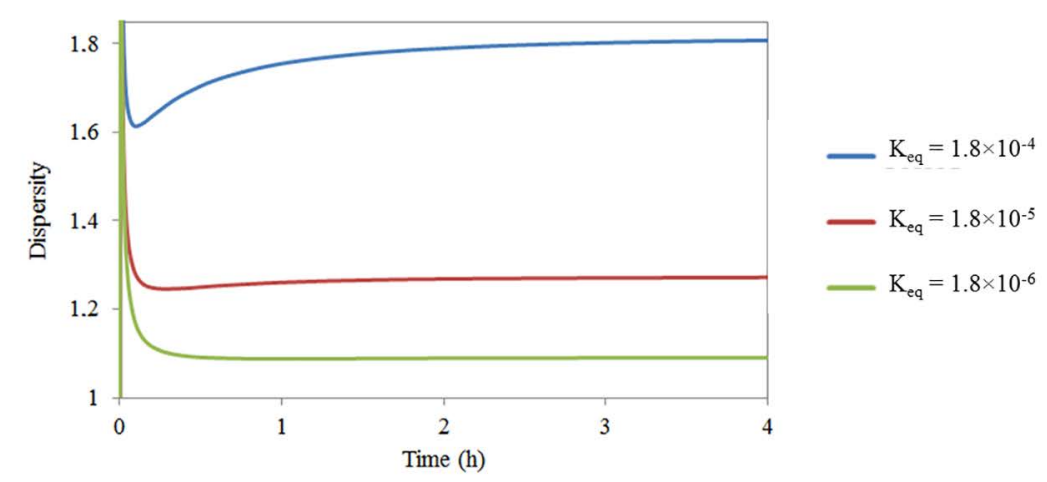

(a)

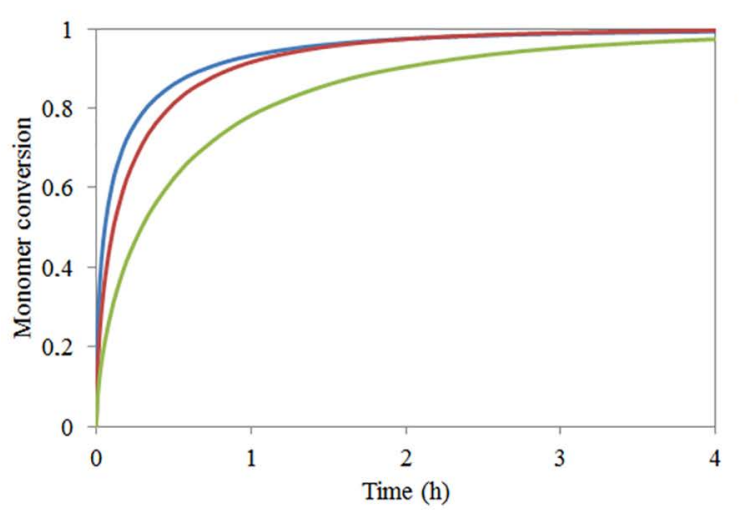

(b)

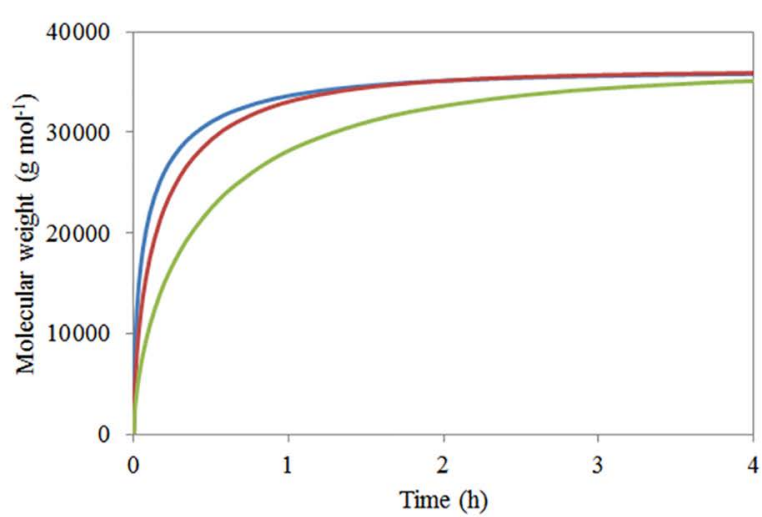

(c)

Figure 5. Analysis of equilibrium constant effect on polymer properties

Figure 5 (a) also indicates that for $\mathrm{K}_{\mathrm{eq}}=1.8 \times 10^{-4}$, there are a strong deviation from polymerization control, suggesting that there is a threshold for the $\mathrm{K}_{\mathrm{eq}}$ around $10^{-5}$, above which there is no ATRP typical behavior. In general, by increasing $\mathrm{k}_{\mathrm{da}}$, the equilibrium is shifted towards higher dormant chain concentrations. Having more dormant chains in the system decreases monomer conversion and degree of polymerization (for the same time). On the other hand, a higher $\mathrm{k}_{\mathrm{da}}$ improves the control over the chain length distribution and, hence, produces polymers with smaller dispersities ${ }^{16,56}$.

Figure 5 (b) shows the monomer conversion as a function of time for the same three values of equilibrium constants, in which it is possible to observe that, as the equilibrium constant increases, monomer conversion also increases. Thus, when $\mathrm{K}_{\mathrm{eq}}=1.8 \times 10^{-6}$, in the first minutes the conversion is significantly increased and at the time of $4 \mathrm{~h}$ unit is reached. For other values, the increase occurs more rapidly. Thus, when referring to the polymerization kinetics, it is possible to see that, for high equilibrium constants, it increases significantly and tends to be smaller for a controlled radical polymerization.

The lower equilibrium constants $\left(10^{-8}-10^{-10}\right)$ are the most ideal for a controlled synthesis using ATRP; however, considering design issues, it could be very small depending on $\mathrm{K}_{\mathrm{eq}}$ value, decreasing considerably the polymerization rate.
Based on these results, it is possible to infer that for the polymerization of tBMA, it would be interesting to choose catalytic systems that provide equilibrium constant values around $10^{-5}$, in order to ensure dispersities less than 1.5 , with a high rate of polymerization. In addition, for the molecular weight (Figure 5 (d)), as the equilibrium constant increases, the number-average molecular weight also increases, following the monomer conversion behavior. However, the magnitude of the molecular weight will be controlled by manipulating the amount of initiator as described in the previous section.

\section{Conclusion}

This paper investigated operational conditions and equilibrium constant effect on chemical species kinetics and poly(tert-butyl methacrylate) properties. The simplified model developed fitted the experimental data in a satisfactory manner. Simulation results showed that tBMA conversion is initiator and dependent on catalyst concentration. Although for the highest initiator proportion there was a dispersity increase in conversions less than $20 \%$, in general, for tBMA ATRP, the range of operational condition cannot affect dispersity directly, which is a very good result in terms of material processability and applications. 
In addition, it was verified that higher values of equilibrium constant could not cause loss to the polymerization control if the threshold for the $\mathrm{K}_{\mathrm{eq}}$ (around $10^{-5}$ ), is respected. Therefore, to conduct tBMA ATRP, it would be very interesting to use catalyst systems with $\mathrm{K}_{\mathrm{eq}}$ ranging from $10^{-6}-10^{-5}$.

\section{Acknowledgments}

This study was funded by "Fundação de Amparo à Pesquisa do Estado de São Paulo", FAPESP (Grant number 2018/02508-5). This study was also partly financed by the "Coordenação de Aperfeiçoamento de Pessoal de Nível Superior" - Brasil (CAPES) - Finance Code 001. The authors thank Espaço da Escrita - Pró-Reitoria de Pesquisa - UNICAMP - for the language services provided.

\section{References}

1. Badri A, Whittaker MR, Zetterlund PB. Modification of graphene/ graphene oxide with polymer brushes using controlled/living radical polymerization. Journal of Polymer Science Part A: Polymer Chemistry. 2012;50(2012):2981-2992. DOI: 10.1002/pola.26094

2. Chmielarz P, Krys P, Wang Z, Wang Y, Matyjaszewski K. Synthesis of Well-Defined Polymer Brushes from Silicon Wafers via Surface-Initiated seATRP. Macromolecular Chemistry and Physics. 2017;218(11):1700106. DOI: 10.1002/macp.201700106

3. Ye H, Owh C, Loh XJ. A thixotropic polyglycerol sebacatebased supramolecular hydrogel showing UCST behavior. RSC Advances. 2015;5(60):48720-48728. DOI: 10.1039/C5RA08222F

4. Lokhande GP, Jagtap RN. Design and synthesis of polymeric dispersant for water-borne paint by atom transfer radical polymerization. Designed Monomers and Polymers. 2016;19(3):256-270. DOI: 10.1080/15685551.2015.1136534

5. Dong L, Liu X, Xiong Z, Sheng D, Zhou Y, Lin C, et al. Design of UV-absorbing PVDF membrane via surface-initiated AGET ATRP. Applied Surface Science. 2018;435:680-686. DOI: 10.1016/j.apsusc.2017.11.135

6. Lamping S, Otremba T, Ravoo BJ. Carbohydrate-Responsive Surface Adhesion Based on the Dynamic Covalent Chemistry of Phenylboronic Acid- and Catechol-Containing Polymer Brushes. Angewandte Chemie - International Edition. 2018;57(9):24742478. DOI: 10.1002/anie.201711529

7. Blin T, Purohit V, Leprince J, Jouenne T, Glinel K. Bactericidal microparticles decorated by an antimicrobial peptide for the easy disinfection of sensitive aqueous solutions. Biomacromolecules. 2011;12(4):1259-1264. DOI: 10.1021/bm101547d

8. Dong C, Wang H, Zhang Z, Zhang T, Liu B. Carboxybetaine methacrylate oligomer modified nylon for circulating tumor cells capture. Journal of Colloid and Interface Science. 2014;432:135143. DOI: $10.1016 /$ j.jcis.2014.07.003

9. Guo Q, Cai X, Wang X, Yang J. "Paintable" 3D printed structures via a post-ATRP process with antimicrobial function for biomedical applications. Journal of Materials Chemistry B. 2013;1(48):6644-6649. DOI: 10.1039/C3TB21415J
10. Flores-Guerrero M, Elizalde LE, Espinoza JF, De Los Santos G, Telles-Padilla G, Ledezma R. Atom Transfer Radical Polymerization of Methylmethacrylate on the Surface of Single Walled Carbon Nanotubes. Journal of Macromolecular Science, Part A: Pure and Applied Chemistry. 2013;50(6):602-606. DOI: 10.1080/10601325.2013.784549

11. Braunecker WA, Matyjaszewski K. Controlled/living radical polymerization: Features, developments, and perspectives. Progress in Polymer Science. 2007;32(1):93-146. DOI: 10.1016/j. progpolymsci.2006.11.002

12. Krys P, Matyjaszewski K. Kinetics of Atom Transfer Radical Polymerization. European Polymer Journal. 2017;89:482-523. DOI: $10.1016 /$ j.eurpolymj.2017.02.034

13. Georges MK, Veregin RPN, Kazmaier PM, Hamer GK. Narrow molecular weight resins by a free-radical polymerization process. Macromolecules. 1993;26(11):2987-2988. DOI: 10.1021/ ma00063a054

14. Chiefari J, Chong YK, Ercole F, Krstina J, Jeffery J, Le TPT, et al. Living Free-Radical Polymerization by Reversible AdditionFragmentation Chain Transfer: The RAFT Process. Macromolecules. 1998;31(16):5559-5562. DOI: 10.1021/ma9804951

15. Wang JS, Matyjaszewski K. Controlled/"Living" Radical Polymerization. Halogen Atom Transfer Radical Polymerization Promoted by a $\mathrm{Cu}(\mathrm{I}) / \mathrm{Cu}(\mathrm{II})$ Redox Process. Macromolecules. 1995;28(23):7901-7910. DOI: 10.1021/ma00127a042

16. Vieira RP, Ossig A, Perez JM, Grassi VG, Petzhold CL, Peres AC, et al. Styrene ATRP Using the New Initiator 2,2,2-Tribromoethanol: Experimental and Simulation Approach. Polymer Engineering and Science. 2015;55(10):2270-2276. DOI: 10.1002/pen24113

17. Matyjaszewski K. Atom Transfer Radical Polymerization (ATRP): Current Status and Future Perspectives. Macromolecules. 2012;45(10):4015-4039. DOI: 10.1021/ma3001719

18. Rajender N, Suresh KI, Sreedhar B. Comb-like polymergraphene nanocomposites with improved adhesion properties via surface-initiated atom transfer radical polymerization (SIATRP). Journal of Applied Polymer Science. 2018;135(8):45885. DOI: $10.1002 /$ app. 45885

19. Liu Y, Yao K, Chen X, Wang J, Wang Z, Ploehn HJ, et al. Sustainable thermoplastic elastomers derived from renewable cellulose, rosin and fatty acids. Polymer Chemistry. 2014;5(9):31703181. DOI: $10.1039 / \mathrm{C} 3 \mathrm{PY} 01260 \mathrm{C}$

20. Huang L, Liu M, Mao L, Huang Q, Huang H, Zeng G, et al. A facile $\mathrm{FeBr} 3$ based photoATRP for surface modification of mesoporous silica nanoparticles for controlled delivery cisplatin. Applied Surface Science. 2018;434:204-210. DOI: 10.1016/j. apsusc.2017.10.187

21. Rodrigues PR, Vieira RP. Advances in atom-transfer radical polymerization for drug delivery applications. European Polymer Journal. 2019;115:45-58. DOI: 10.1016/j.eurpolymj.2019.03.023

22. Hirsch U, Ruehl M, Teuscher N, Heilmann A. Antifouling coatings via plasma polymerization and atom transfer radical polymerization on thin film composite membranes for reverse osmosis. Applied Surface Science. 2018;436:207-216. DOI: 10.1016/j.apsusc.2017.12.038 
23. Wei Q, Pei X, Hao J, Cai M, Zhou F, Liu W. Surface Modification of Diamond-Like Carbon Film with Polymer Brushes Using a Bio-Inspired Catechol Anchor for Excellent Biological Lubrication. Advanced Materials Interfaces. 2014;1(5):1400035. DOI: 10.1002/admi.201400035

24. Lokhande GP, Jagtap RN. Modified poly(butyl methacrylateb-glycidyl methacrylate) dispersant for solvent-based paint by Reverse Atom Transfer Radical Polymerization. Progress in Organic Coatings. 2016;90:359-368. DOI: 10.1016/j.porgcoat.2015.06.025

25. Xu YY, Li G, Hu Y, Wang Y. Synthesis of Poly(Nisopropylacrylamide)-Block-Poly(tert-Butyl Methacrylate) Block Copolymer by Visible Light-Induced Metal-Free Atom Transfer Polymerization. Macromolecular Chemistry and Physics. 2018;219(17):1800192. DOI: 10.1002/macp.201800192

26. Saha A, Jana S, Mandal TK. Peptide-poly(tert-butyl methacrylate) conjugate into composite micelles in organic solvents versus peptide-poly(methacrylic acid) conjugate into spherical and worm-like micelles in water: Synthesis and self-assembly. Journal of Polymer Science Part A: Polymer Chemistry. 2016;54(18):3019-3031. DOI: 10.1002/pola.28188

27. Maksym-Bebenek P, Biela T, Neugebauer D. Water soluble well-defined acidic graft copolymers based on a poly(propylene glycol) macromonomer. RSC Advances. 2015;5(5):3627-3635. DOI: $10.1039 / \mathrm{C} 4 \mathrm{RA} 09738 \mathrm{~F}$

28. Cho KY, Cho A, Kim HJ, Park SH, Koo CM, Kwark YJ, et al. Control of hard block segments of methacrylate-based triblock copolymers for enhanced electromechanical performance. Polymer Chemistry. 2016;7(48):7391-7399. DOI: 10.1039/C6PY01868H

29. Kanhakeaw P, Rutnakornpituk B, Wichai U, Rutnakornpituk M. Surface-Initiated Atom Transfer Radical Polymerization of Magnetite Nanoparticles with Statistical Poly(tert-butyl acrylate)-poly(poly(ethylene glycol) methyl ether methacrylate) Copolymers. Journal of Nanomaterials. 2015;2015:121369. DOI: $10.1155 / 2015 / 121369$

30. Maksym-B?benek P, Biela T, Neugebauer D. Synthesis and investigation of monomodal hydroxy-functionalized PEG methacrylate based copolymers with high polymerization degrees. Modification by "grafting from". Reactive and Functional Polymers. 2014;82:33-40. DOI: 10.1016/j.reactfunctpolym.2014.05.005

31. Nicolau DV, Cross R. Protein profiled features patterned via confocal microscopy. Biosensors and Bioelectronics. 2000;15(12):85-92. DOI: 10.1016/S0956-5663(99)00072-X

32. Piechocki K, Kozanecki M, Kadlubowski S, PacholczykSienicka B, Ulanski P, Biela T. Controlling the properties of radiation-synthesized thermoresponsive oligoether methacrylate hydrogels by varying the monomer side-chain length; selfcomposite network containing crystalline phase. Polymer. 2018;150:275-288. DOI: 10.1016/j.polymer.2018.07.025

33. Peters JT, Hutchinson SS, Lizana N, Verma I, Peppas NA. Synthesis and characterization of poly(N-isopropyl methacrylamide) core/ shell nanogels for controlled release of chemotherapeutics. Chemical Engineering Journal. 2018;340:58-65. DOI: 10.1016/j. cej.2018.01.009
34. Zhou YN, Luo ZH. State-of-the-Art and Progress in Method of Moments for the Model-Based Reversible-Deactivation Radical Polymerization. Macromolecular Reaction Engineering. 2016;10(6):516-534. DOI: 10.1002/mren.201500080

35. Zhou YN, Luo ZH. Assessment of kinetics of photoinduced Fe-based atom transfer radical polymerization under conditions using modeling approach. AIChE Journal. 2017;63(11):49874997. DOI: $10.1002 /$ aic. 15850

36. Zhou YN, Luo ZH. An old kinetic method for a new polymerization mechanism: Toward photochemically mediated ATRP. AIChE Journal. 2015;61(6):1947-1958. DOI: 10.1002/aic.14792

37. Guo JK, Zhou YN, Luo ZH. Kinetic insight into electrochemically mediated ATRP gained through modeling. AIChE Journal. 2015;61(12):4347-4357. DOI: 10.1002/aic.14969

38. Zhou YN, Luo ZH. Insight into the ATRP rate controlling ability of initiator structure: Micromolecular, macromolecular, and immobilized initiators. Journal of Polymer Science Part A: Polymer Chemistry. 2014;52(15):2228-2238. DOI: 10.1002/pola.27249

39. Zhou YN, Luo ZH. Copper(0)-Mediated Reversible-Deactivation Radical Polymerization: Kinetics Insight and Experimental Study. Macromolecules. 2014;47(18):6218-6229. DOI: 10.1021/ma501335j

40. Toloza Porras C, D'hooge DR, Reyniers MF, Marin GB. ComputerAided Optimization of Conditions for Fast and Controlled ICAR ATRP of n-Butyl Acrylate. Macromolecular Theory and Simulations. 2013;22(2):136-149. DOI: 10.1002/mats.201200074

41. D'Hooge DR, Konkolewicz D, Reyniers MF, Marin GB, Matyjaszewski K. Kinetic modeling of ICAR ATRP. Macromolecular Theory and Simulations. 2012;21(1):52-69. DOI: 10.1002/mats.201100076

42. D'Hooge DR, Reyniers MF, Stadler FJ, Dervaux B, Bailly C, Du Prez FE, et al. Atom Transfer Radical Polymerization of Isobornyl Acrylate: A Kinetic Modeling Study. Macromolecules. 2010;43(21):8766-8781. DOI: 10.1021/ma101736j

43. Li X, Wang WJ, Li BG, Zhu S. Kinetics and Modeling of Solution ARGET ATRP of Styrene, Butyl Acrylate, and Methyl Methacrylate. Macromolecular Reaction Engineering. 2011;5(910):467-478. DOI: $10.1002 /$ mren.201100024

44. Rabea AM, Zhu S. Modeling the Influence of Diffusion-Controlled Reactions and Residual Termination and Deactivation on the Rate and Control of Bulk ATRP at High Conversions. Polymers (Basel). 2015;7(5):819-835. DOI: 10.3390/polym7050819

45. Delgadillo-Velázquez O, Vivaldo-Lima E, Quintero-Ortega IA, Zhu S. Effects of diffusion-controlled reactions on atom-transfer radical polymerization. AIChE Journal. 2002;48(11):2597-2608. DOI: 10.1002/aic.690481118

46. Vieira RP, Lona LMF. Simulation of temperature effect on the structure control of polystyrene obtained by atom-transfer radical polymerization. Polímeros. 2016;26(4):313-319. DOI: $10.1590 / 0104-1428.2376$

47. Mastan E, Zhu S. Method of moments: A versatile tool for deterministic modeling of polymerization kinetics. European Polymer Journal. 2015;68:139-160. DOI: 10.1016/j. eurpolymj.2015.04.018 
48. Zhao Y, Luo YW, Ye C, Li BG, Zhu S. Model-based design and synthesis of gradient MMA/tBMA copolymers by computerprogrammed semibatch atom transfer radical copolymerization. Journal of Polymer Science Part A: Polymer Chemistry. 2009;47(1):69-79. DOI: 10.1002/pola.23121

49. Evan Roberts G, Davis TP, Heuts JPA, Ball GE. Monomer Substituent Effects in Catalytic Chain Transfer Polymerization: tert-Butyl Methacrylate and Dimethyl Itaconate. Macromolecules. 2002;35(27):9954-9963. DOI: 10.1021/ma020719m

50. Buback M, Junkers T. Termination Kinetics of tert-Butyl Methacrylate and of n-Butyl Methacrylate Free-Radical Bulk Homopolymerizations. Macromolecular Chemistry and Physics. 2006;207(18):1640-1650. DOI: 10.1002/ macp. 200600254

51. Vieira RP, Lona LMF. Optimization of reaction conditions in functionalized polystyrene synthesis via ATRP by simulations and factorial design. Polymer Bulletin. 2016;73(7):1795-1810. DOI: $10.1007 / \mathrm{s} 00289-015-1577-\mathrm{Z}$

52. Fischer H. The Persistent Radical Effect: A Principle for Selective Radical Reactions and Living Radical Polymerizations. Chemical Reviews. 2001;101(12):3581-3610. DOI: 10.1021/ cr990124y
53. D'hooge DR, Reyniers MF, Marin GB. Methodology for Kinetic Modeling of Atom Transfer Radical Polymerization. Macromolecular Reaction Engineering. 2009;3(4):185-209. DOI: $10.1002 /$ mren.200800051

54. Vieira RP, Lona LMF. Kinetic modeling of atom-transfer radical polymerization: inclusion of break reactions in the mechanism. Polymer Bulletin. 2016;73(8):2105-2119. DOI: 10.1007/s00289-015-1596-9

55. Preturlan JGD, Vieira RP, Lona LMF. Numerical simulation and parametric study of solution ARGET ATRP of styrene. Computational Materials Science. 2016;124:211-219. DOI: 10.1016/j.commatsci.2016.07.038

56. Vieira RP, Ossig A, Perez JM, Grassi VG, Petzhold CL, Peres A, et al. Simulation of the equilibrium constant effect on the kinetics and average properties of polystyrene obtained by ATRP. Journal of the Brazilian Chemical Society. 2013;24(12):20082014. DOI: $10.5935 / 0103-5053.20130251$

\section{Supplementary material}

The following online material is available for this article: Appendix 